\title{
Business Executives Sharing Knowledge with Inference Engines: News from the ONTORULE Project
}

\author{
Christian de Sainte Marie \\ IBM, 9 rue de Verdun, 94253 Gentilly, France \\ csma@fr.ibm.com
}

\begin{abstract}
The EC-funded ONTORULE project ${ }^{1}$ was started with the stated objective of realizing the old promise to give back to the business user the ownership and control over the business knowledge that is put to action in business applications. The project team identified several conditions that must be satisfied to achieve that objective, including: i) the separation of conceptual and operational knowledge at all levels; ii) the separation of the business representation of the knowledge, from its operationalization and from its implementation in business applications; iii) the provision of tooling to handle and manage the mapping between the different representations, the recombination of the different kinds of knowledge, and the inter-dependencies between all of them. This talk will present and discuss the progress made in ONTORULE and the results of the project to this point. All the public deliverables of the project are downloadable from the project web site, as well as technology prototypes, demonstrators, and a list of publications ${ }^{2}$.
\end{abstract}

1 The ONTORULE project is partially funded by the European Commission under Grant Agreement $\mathrm{n}^{\circ} 231875$.

2 www. ontorule-project.eu 